\title{
Developing a Gendered Participatory Prevention Counselling Approach for Gender Based Violence among Soldiers Families in Eastern, Zambia.
}

\author{
John Mwitumwa Matakala ${ }^{1}$, Margaret Milochi Nzima ${ }^{2}$, Ivy Nawa Akabondo ${ }^{3}$, Mubiana \\ Macwan'gi ${ }^{4}$, Anne-Namakando Phiri ${ }^{5}$ \\ Department of Gender Studies, University of Zambia, Lusaka; Zambia
}

*Corresponding Author: John Mwitumwa Matakala, Department of Gender Studies, University of Zambia, Lusaka; Zambia

\begin{abstract}
The aim of the thesis was to develop a Gendered Participatory Prevention Counselling Approach for Gender Based Violence among Soldiers families through social action. The study was grounded on the Interprativist Emancipation Phenomenology study design. Purposive and respondent driven sampling were used to come up with the desired sample size of the study and the resultant data were collected in two phases. The first phase came up with responses to the first three prerequisite standardized knowledge or questions on the problem as a requirement and phase two came up with the new innovation based on a selected gendered group of victims which resulted into a localized counselling prevention gender based violence model as the research output. Data collection was collected using both in-depth and focus group discussions interviews. The findings were thermatized chronologically in line with research questions before action by selected victims. The findings on the gaps in programs of counselling prevention of gender based violence showed none was there, but just a gender desk in its infancy at Army Headquarters. The findings on the contributing factors show lack of knowledge on sexual harassment. The findings of the characteristics for both male and female victims were seen through abuse of authority. The findings on the types of sexual harassment for the victims were verbal and non-verbal harassment for the females while verbal harassment was established from the males. As per requirement, the researcher provided an action agenda for change in form of a question, which was used with a selected gendered focus group team of victims who developed Quadruple Participatory Prevention Counselling Model for Gender Based Violence among Soldiers families. The findings showed that if sexual harassment was not put on check it would affect the gendered input of the victims at work. It is against this background a more practical and workable solution based on victims input has been adopted for implementation by military authorities.
\end{abstract}

Keywords: Developing a Gendered Participatory Prevention Counselling Approach, Gender Based Violence, Counselling, Soldiers Families.

\section{INTRODUCTION}

\subsection{Background to the Study}

Much has been documented worldwide, on Gender Based Violence due to its existence and this has been alluded due to lack of a proper defined counseling strategies especially among Sub-Saharan African Countries. This has led to fatal injuries and emotional stress which many times has resulted into deaths for both men and women in various communities that also includes military communities WHO (2008). This is a source of concern as Zambia's Geo-Position is within the same area. While the majority of the victims are females it must be noted that the males are also not excluded.

The United Nations through the 'United Nations Entity for Gender Equality and the Empowerment of Women' was one of the agencies that was concerned with the issue of Gender Based Violence which is also synonymous with sexual harassment. It argued that member states were to ensure that work places such as the military and nonmilitary communities were to ensure that the female were protected from the vice. It went on to state that even the male military personnel were to be protected. This is because on both male and female are potential victims gender based violence through physical infliction of bodily harm and emotional that might reasonably be expected or be perceived to cause humiliation to another person leading to death (EEOC, 2006). 
One of the Sub Saharan Countries that criminalized Gender Based Violence was Zambia. It did so through the Act No. 1 Anti-Gender Based Violence whose date of accent was on 12 April 2011. The act may be cited as Anti-Gender Based Violence of Act 2010. It was subsequently criminalized.

In the Preambo

\section{"Gender Based Violence is any Physical, Mental, Social, or Economic \\ Abuse against a person because of the persons Gender. In this case \\ The context otherwise requires abuse means that causes harm \\ Or wounding of the victim or emotional harm".}

"physical abuse" means physical assault or use of physical force against another person, including the forcible confinement or detention of another person and the deprivation of another person of access to adequate food, water, clothing, shelter, rest, or subjecting another person to torture or other cruel, inhuman or degrading treatment or punishment; " physical, mental, social or economic abuse " means any act, omission or behaviour or threat of any such act, omission or behaviour which results in death or is likely to result in the direct infliction of physical, sexual or mental injury to any person, and includes - (a) physical abuse; (b) sexual abuse; (c) emotional, verbal or psychological abuse, including any conduct that makes another person feel constantly unhappy, humiliated, ridiculed, afraid or depressed or to feel inadequate or worthless; (d) economic abuse; (e) intimidation; $(f)$ harassment; $(g)$ stalking; $(h)$ controlling behaviour such as isolating a person from the person's family and friends, monitoring the person's movement and restricting the person's access to information or assistance; (i) malicious damage to property; (j) forcible entry into a person's residence, where the parties do not share the same residence; $(k)$ depriving a person of, or hindering a person from access to or a reasonable share of the use of the facilities associated with the person's residence or forcible entry into a person's room or into a room occupied by a person, where the parties share the same residence; (l) the unreasonable disposal of household effects or other property in which a person has interest; $(m)$ abuse delivered from the following cultural or customary rites or practices: (i) forced virginity testing; (ii) female genital mutilation;

\section{No. 1 of [2011] Anti-Gender-Based Violence}

The above mentioned are classified as felony and may attract a jail sentence of between three to fifteen years.

In order to ensure effectiveness, the victim support unit under the Zambia Police was established with a mandate of prosecuting investigating and arresting of the perpetrators of gender based violence. It was also with a view to giving of advice.

Despite these mitigation measures it appears the vice is said to be on the increase as shown by Who, 2008.

According to ZDHS (2007) Showed that Gender Based Violence in form of physical violence does exist in Zambia with the highest statistics coming from the Eastern Province. World Vision (2015) states that the One Stop Centers for gender based violence victims involves Special homes that have been set up to counsel them. This is with the assistance of community -led anti Gbv efforts from Chiefs Kalindawalo and Nyampande in eastern province.

Many research studies have since been conducted which ended at providing recommendations as a solution based on the inquirer perspective Holahan and Moos (1997), Swart (2011) Musune (2015), and Mutakwa (2016).

Mwanza (2016) did an evaluation of the one stop center for counselling of gender based violence victims in eastern province, but also ended at providing of recommendations.

The identified problem is that none of the studies developed a gendered counselling strategies through the participatory approach by the research process of social action Egaden (2012). However, it appears literature on social action as a solution to gender based violence has not been done. Therefore the study will adapt the principles and approach from a study conducted in Canada among some female officer cadets with regard to sexual harassment a phenomenon which in one way or the other is synonymous to gender based violence. 
This study began by coming up with pre requisite standardized knowledge on the problem before coming up with recommendations that were used as action agenda for change questions in order to come up with prevention strategies from a selected group of the cadets using the participatory approach through social action process. The researcher then gave meaning to the views before bringing them back for adoption. The resultant research output was a localized prevention model Merriam (2015).

This inquiry will adopt the principles and approach for this study in order to fill in the knowledge gap under scrutiny.

\subsection{Statement of the Problem}

The available empirical evidence shows that it appears, there is no study that has developed a Gendered Participatory Prevention Counselling Approach among Gender Based Violence families of Soldiers in Eastern, Zambia.

Therefore, this is a compelling knowledge gap. 1.2. GENERAL OBJECTIVE: To develop a "gendered participatory counselling approach" for Gender Based Violence victims through social action.

\subsection{Specific Objectives}

(1) To assess knowledge of the existing gaps in counselling programs for Gender Based Violence (2) To identify the types of counselling services offered to the Gender Based Violence victims (3) To establish the characteristics of Gender Based Violence (4) To develop counselling strategies for Gender Based Violence using a gendered participatory approach.

\subsection{Specific Objectives}

(1) What is your knowledge of the existing gaps in counselling programs for Gender Based Violence

(2) What types of counselling services are offered to the Gender Based Violence victims (3) What are the characteristics of Gender Based Violence (4) How can counselling strategies for Gender Based Violence be developed using a gendered participatory approach.

\subsection{Significance of the Study}

This study is ground breaking because it will develop a "gendered participatory prevention counselling approach" for Gender Based Violence among families of soldiers in Eastern, Zambia through social action. The innovation will further be forwarded to policy makers for practical implementation at the Ministry of Defense or the Army. It is also hoped that it will act as a stepping stone for further research.

\subsection{Definition of Terms}

(1) Social Action: Is a two phased inquiry which begins by finding answers through participant experiences from prerequisite standardized research questions, after which the researcher develops an action agenda for change, which is used for establishing ways for preventing sexual harassment based on victim ideas under his guidance.(2) Gendered Participatory Prevention Counselling Approach: Is a practical way in which male and female victims come up with counselling strategies for Gender Based Violence through a focus group discussion with the researcher (3) Gender Based Violence: Are physical violence perpetrated between people of the opposite that is men and women in marriage leading to physical or emotional injury (4) Counselling: is a talking therapy that allows people to bring about their problems in a safe and confidential environment with a view to stop an act of violence in the clients mind. Or (5) Counselling: is mutual helping relationship that is between a person in need of help (client) and a trained (counsellor) for future change or modification of behavior to an accepted behavior using the principles that are prescribed Ndhlovu (2015)

\section{Methodology}

A qualitative research approach was used grounded in the Interpretivism Participatory Philosophy in order to understand the lived Gendered experiences and interpretations of gender based violence among families of soldiers. This was done in order to develop Prevention Counselling Strategies Through the desired plan. 
(1) How was the Research Plan and Design of the Inquiry?

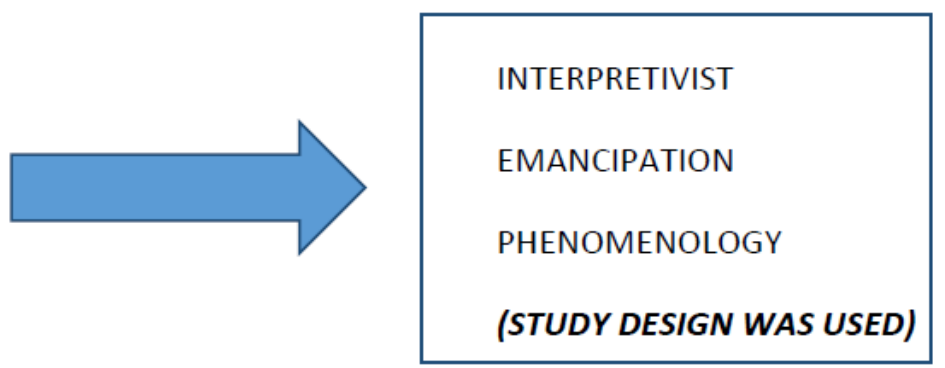

The philosophy that informed the study design as alluded in the Preambo was the Interprativist Participatory Philosophy because it allows both the researched (Participants) and the researcher to be a part to the solution.

\subsection{Interpretivist Emancipation Phenomenology}

As a plan for this study, did explore and understand gender based violence based on the experiences of participants and the researcher through social or emancipation action. See 1.7.

This was achieved through data collection and analysis of the first three prerequisite standardized questions or knowledge on the problem as a requirement in the first phase of the inquiry See 1.3.1. An action agenda for change in form of a question at the commencement of the second phase of the inquiry was prepared for use by a selected gendered group in order to come up with prevention counselling strategies of gender based violence using the participatory approach. They were guided by the researcher and formal communication was done to those selected about the focus group procedures. The group having come up with prevention counselling strategies through the process of social action as per requirement allowed the researcher to give meaning to the data before taking them for final adoption which resulted into the localized prevention counselling model for gender based violence.

The whole plan of the inquiry is shown hereunder;

Data Gathering: involved the use of In-depth and focus group interviews on a population of all military victims that will make up the desired sample size.

Data Analysis: involved the use of qualitative software in order to reduce the resultant bulk data to under stable themes and sub themes.

Communication: An action agenda for change prepared by the researcher in form of a question is prepared for perusal by a group of selected participants in readiness for use in coming up with prevention counselling strategies for gender based violence.

Corroboration: The group guided by the researcher comes up with prevention strategies for gender based violence and are not disturbed which was phenomenology reduction. This was followed by giving of meaning to the responses by the researcher before final adoption hence satisfying the type of research design which not only allows phenomenology reduction of being passive but to also bring in his ideas. Such a design was adopted from the works of Martin Heidegger a phenomenology scholar (Egaden, 2012).

A Further detailed analysis of the process using the social action principles is shown hereunder;

Process of Developing a Participatory Prevention Counselling Approach Using Social/Emancipation Action Principles.

\begin{tabular}{|l|}
\hline \multicolumn{1}{c|}{ 1.GENERATING FORMATIVE INFORMATION (PHASE ONE) } \\
\{Pre Requisite Standardized information on the problem based on gendered Perceptions\} \\
\hline The reason is because there is no Gendered Participatory Prevention Counselling approach for \\
gender based violence among Soldiers families in Zambia. \\
The Pre Requisite standardized questions from gendered perceptions are; \\
a. Identification of gaps in intervention Counselling Prevention Programs of Gender Based \\
$\quad$ Violence. \\
b. Types of Counselling Prevention strategies for Gender Based Violence. \\
c. Characteristics of Gender Based Violence.
\end{tabular}


Developing a Gendered Participatory Prevention Counselling Approach for Gender Based Violence among Soldiers Families in Eastern, Zambia.

2.Developing The Participatory Prevention Counselling Approach (Phase Two)

- Selection criteria for participants and their areas of origin to engage in the group Emancipation

a. Only male and female victims of Gender Based Violence where purposively selected to form part of the group.

b. They had lived in the area for not less than three years.

c. Further those to be included where in the classes of physical and emotional abuse/violence.

- $\quad$ Selection areas of the participants

a. Eastern, Zambian bases.

- Eliciting of prevention counselling strategies of gender based violence from the gendered emancipation group (Corroboration)

a. An Action Agenda for Change in form of a predetermined question by the researcher was used to elicit the prevention counselling ways for gender based violence from the group under the guidance of the researcher who also took down the notes on an interview protocol or script of each participant' s contribution as the group was interacting as a team.

- Analysis and Interpretation of input from the participants

a. Upon the completion of the collection of the prevention counselling strategies from the group the researcher proceeded to give meaning to the input.

- Validation and Consensus building with the group

a. After having given meaning to the prevention counselling ways of the group through the participatory approach, the researcher returns back the information back to the participants for the final adoption completing the social action research process.

b. The participatory approach input is given a formal identification model name.

(2) What Was The Nature Of The Reality And Research Approach In The Inquiry?

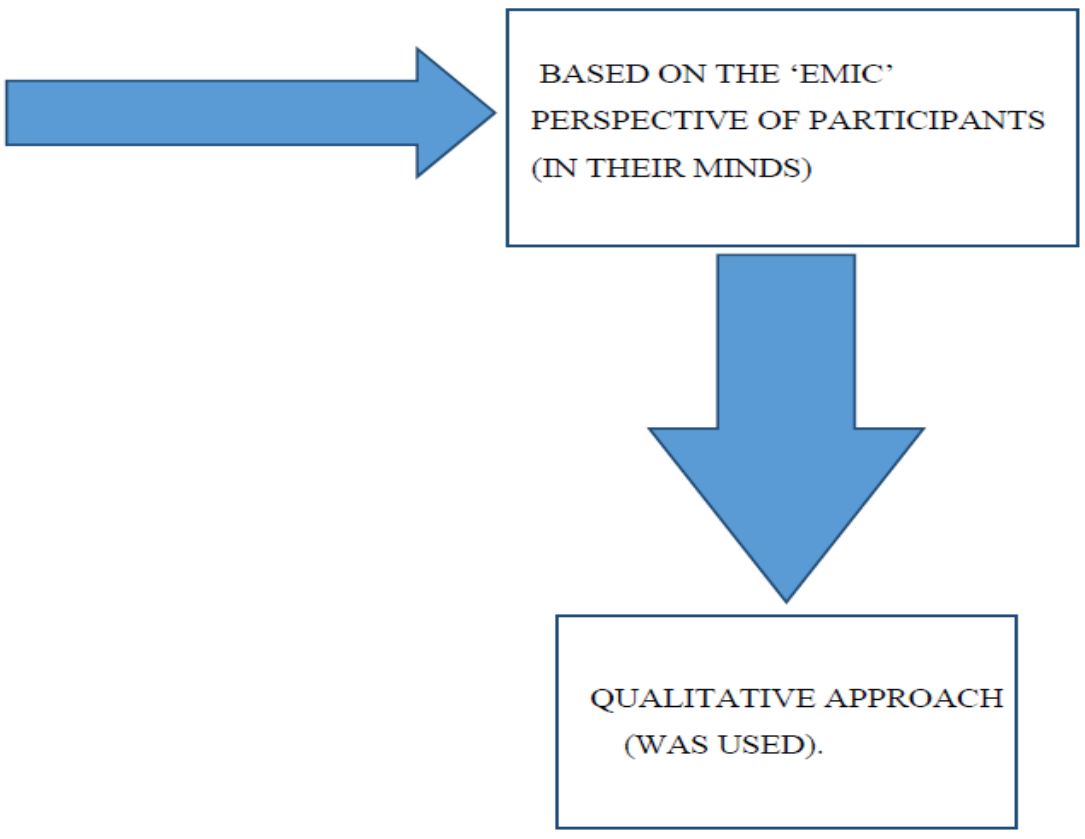

The Nominalist Ontology Philosophy in a research provides the answer to the question on the reality that is being pursued in a given inquiry.As a philosophy itstates that data as a 'Reality' of for the prevention counselling strategies on gender based violence came from lived experiences and interpretations that are based on the 'Emic' perspective meaning the ideas and perceptions are from the insider's view. The researcher and the researched who are participants could not therefore be separated hence the qualitative approach and principles was the most ideal in this inquiry.

Since the reality will be based on the emic perspective this philosophy points to a qualitative approach which in terms of methodology is determined by the main paradigm (Holloway and Wheeler, 1996). As shown in 3.1. 
Developing a Gendered Participatory Prevention Counselling Approach for Gender Based Violence among Soldiers Families in Eastern, Zambia.

(3) How Did We Know What We Did Not Know/Analysis In The Inquiry?

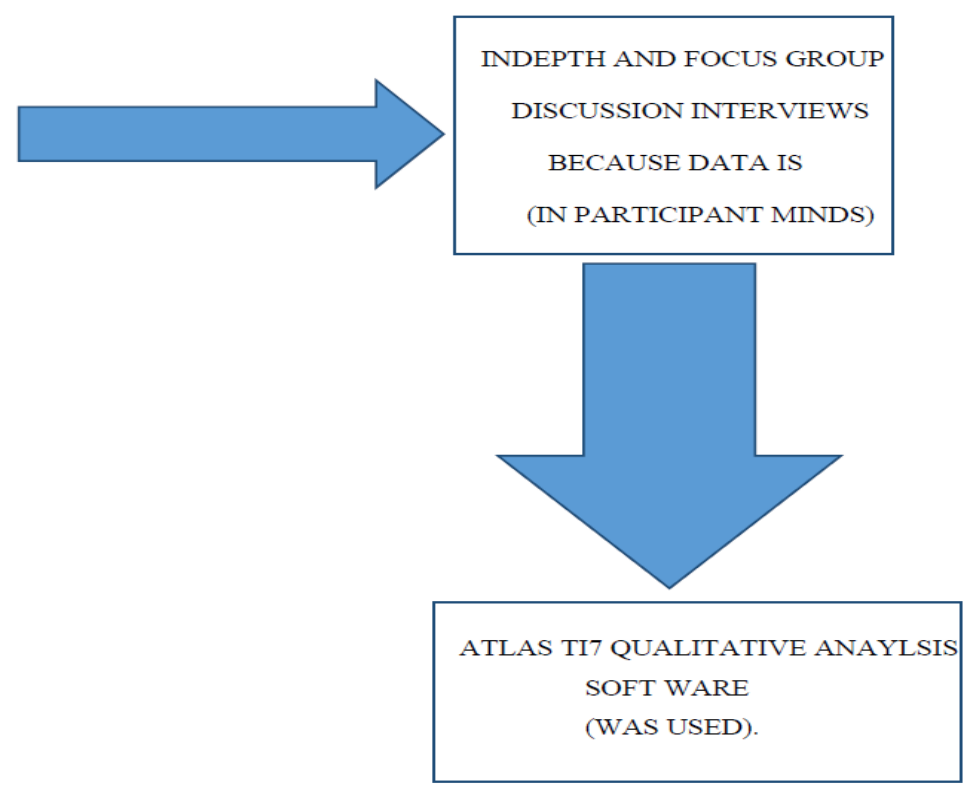

The Interprativist Epistemology Philosophy in a research provides the answer to the question on how to know what is not known in terms of the pursued reality through face to face interview in a given inquiry. As a philosophy it states that the knowledge of prevention counselling of gender based violence from the perceptions of the participants in terms of lived experiences and interpretation came from disclosure through interviews.

Since the lived experiences and interpretations of the phenomenon will came through disclosure this philosophy points to unstructured interviews for the methodology as way get this knowledge through the use of in-depth and focus group discussion interviews. These qualified because they were able to come up with in-depth understanding of the phenomenon under scrutiny. It also allowed for opened ended questions that are ideal for the inquiry. (Guba and Lincoln, 1994).

The resultant data were analysed through the use of qualitative software called Involves the use of Atlas TI7.It is a software for qualitative inquiry meant to reducing the large amounts of data into themes and categories that are understandable (Mohammed, 2014). It began by opening the hermeneutic unit, which is the main coding tool. Once it was opened the data was fitted in with raw data on the unit editor on the quotation folder, then the code button was clicked. Themes and subthemes were created by clicking the useful words for clear understanding.

(4) How Was The Sample Size And Mode Of Selection Of Participants In The Inquiry?

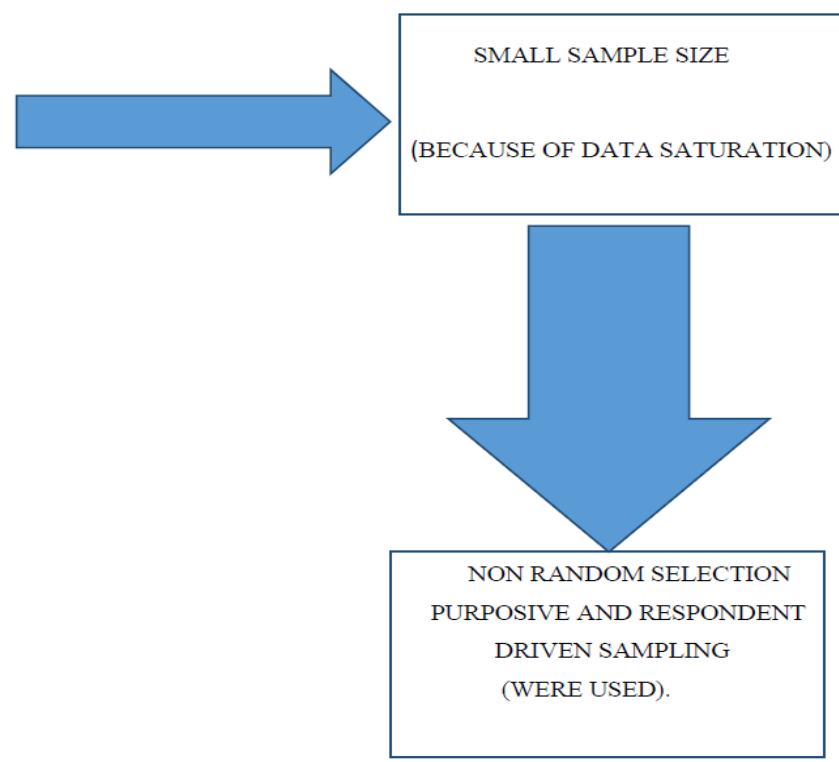


The Idiographic Methodological Philosophy in a given research provides answers to the question on the sample size and the selection mode of participants.

It is a philosophy, states that fewer participants will be selected through Non random sampling from a problematic population in order to understand the interpretations of a phenomenon like prevention counselling on gender based violence. This meant that it informed the methods part to make use of the purposive sampling supplemented by the respondent driven sampling in order to come up with the desired sample size from a population of all gender based victims who would help in coming up with prevention counselling strategies through the participatory approach in terms of what we did not know using the social action process. In the initial stage physical interviews revealed the participants that could give answers to the research questions through the purposive sampling. The first group representative one each by sex in both urban and rural were then asked to recruit their peers until their targets were met in order to come up with the desired sample size.

The sample size was small because data normally reaches its limit in any inquiry between one to three participants if they are from a homogenous population. Usually the next participant will come up with repeated data. Thereafter data may be analysed at the third participant level because of data saturation which means no newer information will be realized. Holloway and Wheeler (1996).

Since a small sample was required from non-random sampling methods this philosophy directs the methodology to utilize the purposive and the respondent driven sampling and its techniques in order to pick the desired sample size (Leedy and Omorod, 2005).

Adapted from Egaden (2012)

(5) How Were The Data Quality Issues Taken Care Of In The Inquiry?

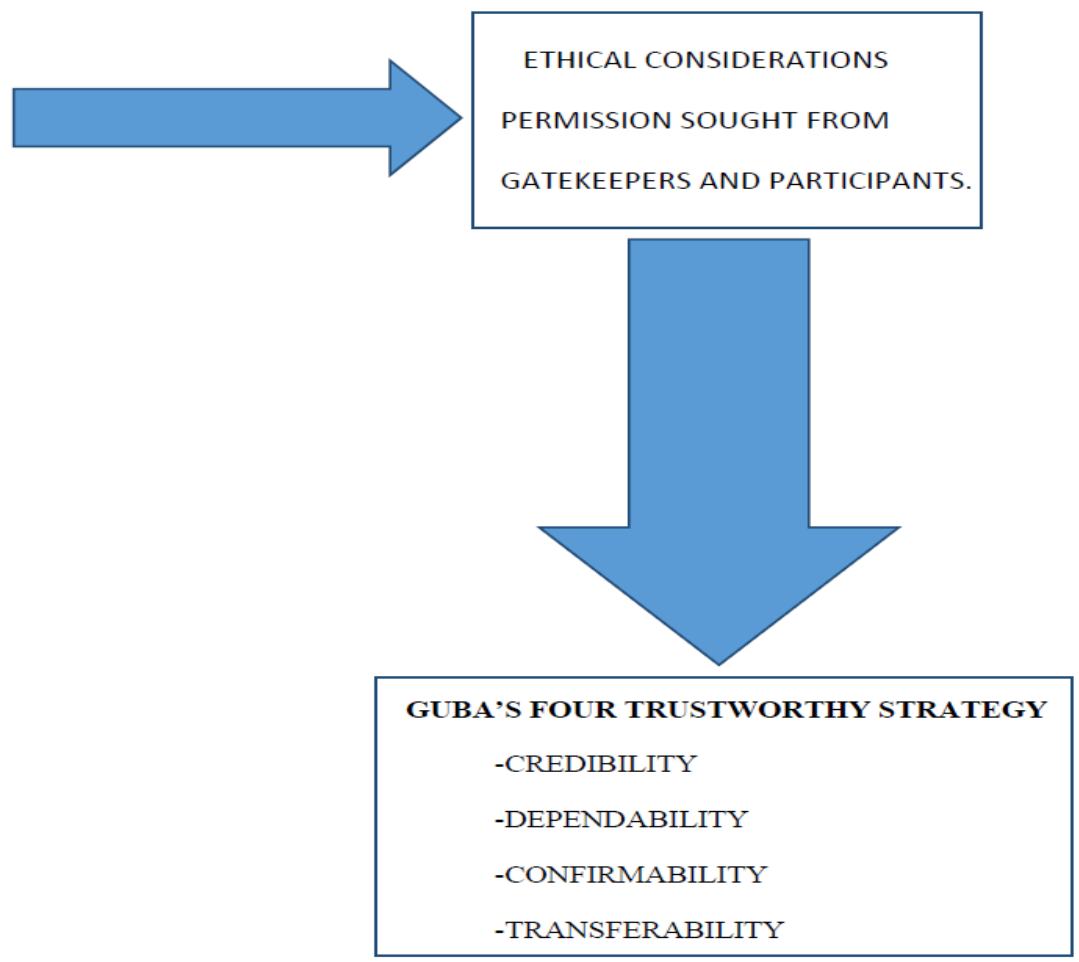

The answer to the quality issues were achieved through the ethical considerations and trustworthiness.

The ethical consideration in this inquiry were meant to get permission from the military authorities and was followed by permission from the participants willingly through the use of the verbal or written consent after the informed consent form has been read.

Trustworthiness involved the use of Guba's four trustworthy strategies: These are; Credibility: Which was assured through choosing the correct design? Transferability: Which was assured through contextualizing with other studies? Dependability: Which was assured through making instruments to be reliable? Confirmability: Which was ensured through 'bracketing' or 'epoche' by taking information as it comes and not interrupting it? (Guba and Lincoln, 1994). 
This meant that through the use of the aforementioned data quality was assured meaning that the study has met the underlying acceptable academic standards.

(6) How Did The Researcher Maintain Research Confidence From The Researched (Participants) In The Inquiry?

This was achieved through the use of reading the informed consent form which is shown hereunder.

\section{INFORMED CONSENT FORM}

Dear participants,

This serves to give you an understanding of the research and procedures that will be followed.

Similar information in this form will be read to you alongside the questions with regard to each objective and its research instrument.

Further the implications for your participation are explained below, finally you are asked to sign this form to indicate that you have agreed to participate in this exercise.

Thanking you in advance.

\section{- Description}

This is an educational research; the researcher is a student at the University of Zambia pursuing a Doctor of Philosophy in Gender Studies.

This research is a contribution to academic knowledge. Therefore, this study is purely academic.

\section{- Purpose}

The researcher wishes to Develop a Gendered Participatory Prevention Counselling Approach for Gender Based Violence among Soldiers families in Zambia and it is going to be purely a phenomenological perspective under the Interpretivism participatory philosophical paradigm. The researcher is interested in assessing of gaps existing in intervention prevention counselling programs of gender based violence, types of counselling programs, and characteristics of gender based violence. The researcher having found answers to the pre requisite standardized question on the problem as per requirement in the first phase of the inquiry. At the commencement of phase two the will come up with an action agenda for change in form of a question as per requirement which will be used by the participants to develop the innovation guided by the researcher. The developing of a Gendered Participatory Prevention Counselling Approach for gender based violence is based on victim ideas using focus group discussion embedded in the participatory approach guided by the researcher there by completing Social Action emancipation process which will give a research output of a Prevention Counselling Model for Gender Based Violence for military families.

\section{- Consent}

Participation in the exercise is voluntary. You are free to decline to participate in this exercise.

\section{- Confidentiality}

All data collected from this research is treated with utmost confidentiality. Participants are assured that they will remain anonymous and untraceable in this research.

It is against this background that participants will only be identified through a number and not by name or pseudo names will be used.

\section{- Rights of participants}

All efforts will be taken to ensure that the rights of participants as per research ethics are protected and respected. Participants are assured that they are free to ask for clarification at any point of the exercise and to inform the researcher if they feel uncomfortable about any procedure in the research. 
Developing a Gendered Participatory Prevention Counselling Approach for Gender Based Violence among Soldiers Families in Eastern, Zambia.

Your consent to this request will be highly valued and appreciated.

JOHN MWITUMWA MATAKALA-PhD Research Fellow.

\section{- Declaration of Consent}

I have read or head and fully understand this document concerning the research. Therefore voluntarily I have agreed to participate in this study.

Participant number Signature

Date:

Adapted from Holloway and Wheeler (1996)

\section{RESUlTS \& Discussion}

\subsection{What is your Knowledge on the Existing Gaps in the Prevention Counselling Approach for Gender Based Violence among Soldier's Families?}

\subsubsection{Contextualised Similarities with Other Empirical Studies}

\begin{tabular}{|l|l|}
\hline $\begin{array}{l}\text { Empirical Findings on existing gaps in } \\
\text { prevention counselling approach for gender } \\
\text { based violence }\end{array}$ & $\begin{array}{l}\text { Research Findings on existing gaps in prevention } \\
\text { counselling approach for gender based violence } \\
\text { among soldiers families for this Study }\end{array}$ \\
\hline $\begin{array}{l}\text { Studies by Mutakwa (2015) from the victim } \\
\text { support as an informant, that they punish, } \\
\text { caution and offer advice to the perpetrator } \\
\text { not to repeat. }\end{array}$ & $\begin{array}{l}\text { The findings of this study are in agreement with the } \\
\text { other study in that it also found that it was similar to } \\
\text { the study of Mutakwa. }\end{array}$ \\
& $\begin{array}{l}\text { This happens when they are taken to the police. } \\
\text { The reason for this similarity is that similar findings } \\
\text { take place in homogenous or same environments } \\
\text { and similar cases. }\end{array}$ \\
\hline
\end{tabular}

Source: Field Data (2017) and Empirical Literature

This is what the participants had to say when asked on the existing gaps in prevention counselling for Gender Based Violence among soldier's families;

A wife of a soldier by the name of Jennifer (Pseudo name) whose husband is of the rank of staff sergeant when asked on the existing gaps on prevention counselling for gender based violence had this to say;

"Pamene bananimenya bamuna banga bana baika mu ma celu in Chinyanja which in English when my husband hit me I reported him to The police who put Him in the police cells....... when I went to release him he was cautioned Not to repeat and the counselling offered was not to repeat because it Lead to a jail sentence...

A civilian husband of a soldier by the name of Joachim (Pseudo name) whose wife is of the rank of sergeant when asked on the existing gaps on prevention counselling for gender based violence had this to say;

'Sir 'meaning the researcher' my wife is a soldier. When she assaulted me at

Hospital I was told a medical report was needed before being attended. I was

Told it was to bring the perpetrator when she arrived she identified herself

And was just cautioned and advised to stop. We were not counselled

As a couple on the root cause of the problem

\subsubsection{Contextualised Disimilarities with Other Empirical Studies}

This study came up with findings that were not similar with other studies at global level. The study established that when cases where reported to the immediate the perpetrator was punished, cautioned and advised not to repeat the act again as it was going to lead to consequences that would affect him badly at work. No study came up with this finding. 
The reason for this difference is differential cultural backgrounds and philosophy.

This is what the participants had to say when asked on the existing gaps in prevention counselling for Gender Based Violence among soldier's families;

A wife of a soldier by the name of Jenny London (Pseudo name) whose husband is of the rank of sergeant when asked on the existing gaps on prevention counselling for gender based violence had this to say;

'Sir 'meaning the researcher' when I reported my husband for hitting me

I was told that they were going to get back to me and the next thing I heard

Was that he had been punished. He was later cautioned and advised not to

Repeat the act again What was surprising is that I was not

Called so that the problem is solved together as a team

\subsection{What Types of Prevention Counselling Programs do you have for Gender Based Violence among Soldier's Families?}

\subsubsection{Contextualised Similarities with Other Empirical Studies}

It must be noted that it appears from the interacted empirical literature there are no studies that were recorded. The under mentioned findings hence constituted new knowledge.

\subsubsection{Contextualised Disimilarities with Other Empirical Studies}

This study came up with findings that were not similar with other studies at global level. The study established that there are no defined prevention programs for gender based violence due to several lapses in the way they are handled by stake holders such as the police and military authorities. These require to be strengthened.

This is what the participants had to say when asked on the types of prevention counselling programs for Gender Based Violence among soldier's families;

A wife of a soldier by the name of Jennifer (Pseudo name) whose husband is of the rank of staff sergeant when asked on the types of prevention counselling programs for gender based violence had this to say;

"Sir as I have already said with regard to the question earlier on during the interview

When my husband hit me I reported him to the police.

The police who put Him in the police cells...... when I went to release him he was

Cautioned Not to repeat and the counselling offered was not to repeat because it

Lead to a jail sentence.

For me on that question I can simply say there is no defined program because we

Not asked as a couple the root cause of the problem.....

A civilian husband of a soldier by the name of Joachim (Pseudo name) whose wife is of the rank of sergeant when asked on the existing gaps on prevention counselling for gender based violence had this to say;

'Sir 'meaning the researcher' my wife is a soldier. When she assaulted me at

The police, we were not counselled as a couple on the root cause

of the problem ....................................Because of that I can say that

there are no defined programs both at the police as a stakeholder as well

the military 
Developing a Gendered Participatory Prevention Counselling Approach for Gender Based Violence among Soldiers Families in Eastern, Zambia.

\subsection{What are the Characteristics for Gender Based Violence among Soldier's Families?}

\subsubsection{Contextualised Similarities With Other Empirical Studies}

\begin{tabular}{|c|c|}
\hline $\begin{array}{l}\text { Empirical Findings on characteristics for } \\
\text { gender based violence }\end{array}$ & $\begin{array}{l}\text { Research Findings on the characteristics for gender } \\
\text { based violence among soldiers families for this Study }\end{array}$ \\
\hline $\begin{array}{l}\text { The research evidence recorded from some } \\
\text { studies show that physical abuse or violence } \\
\text { was more prominent in different environments. }\end{array}$ & $\begin{array}{l}\text { The findings of this study are in agreement with } \\
\text { the other study in that itso found that it was } \\
\text { similar to the other studies shown on the opposite } \\
\text { side. }\end{array}$ \\
$\begin{array}{l}\text { The reason for this similarity is that similar } \\
\text { findings take place in homogenous or same } \\
\text { environments and similar cases. Furthermore, } \\
\text { every community has differences which influence } \\
\text { hysteria leading to physical violence in form of } \\
\text { battery. }\end{array}$ \\
\hline
\end{tabular}

Source: Field Data (2017) and Empirical Literature

This is what the participants had to say when asked on the characteristics for Gender Based Violence among soldier's families;

A wife of a soldier by the name of Linda (Pseudo name) whose husband is of the rank of Corporal when asked on the characteristics for gender based violence had this to say;

'Sir 'meaning the researcher' my hubby slapped me when he came back from

Drinking beer all just because I asked him where he had come from...........

This is Gbv ,'

A civilian husband of a soldier by the name of Mark (Pseudo name) whose wife is of the rank of Corporal when asked on the Characteristics for gender based violence had this to say;

"Sir 'meaning the researcher' my wife is a soldier. When she came late home

Late I asked her for a reason............ She answered in Chinyanja language

By saying Imwe ndimwe ba civilian chabe meaning that I am just a civilian.

When I asked further she slapped me........................"

\subsubsection{Contextualised Disimilarities With Other Empirical Studies}

This study came up with findings that were not similar with other studies at global level. The study established that the characteristics for gender based violence also manifested itself through the emotional abuse or gender based violence due to several lapses in the authorities that have not embraced lasting solutions such as defined counselling process in all gender issues. These require to be strengthened.

This is what the participants had to say when asked on the characteristics for Gender Based Violence among soldier's families;

A wife of a soldier by the name of Peggy (Pseudo name) whose husband is of the rank of Warrant Officer when asked on the characteristics for gender based violence had this to say;

"Sir 'meaning the researcher' my husband refused the food I had

Prepared for him for several days which is affecting my emotions?

I am better of.....

A Military husband of a soldier by the name of Samson (Pseudo name) whose wife is of the rank of Corporal when asked on the Characteristics for gender based violence had this to say;

"Sir 'meaning the researcher' my wife is a soldier. She at times denies me

Rights of a husband........ especially at night even touching her.............and 
Developing a Gendered Participatory Prevention Counselling Approach for Gender Based Violence among Soldiers Families in Eastern, Zambia.

Warns me that if I touched her she will scream that I raped her .."

\subsubsection{Summary of the First Phase of the Inquiry as Per Requirement of the Research Principles and Approach.}

The aim of the first phase of the inquiry was to come up with pre requisite standardized knowledge on the problem, as per requirement in line with the social action principles. It was done with respect to the following pre requisite standardized knowledge on the problem; assessment on the knowledge of intervention prevention counselling programs for gender based violence as a start point for all solutions on prevention through social action Egaden (2012). The other related knowledge on the problem came from the types of counselling prevention programs of gender based violence and the characteristics of gender based violence.

Having come up with the afore mentioned knowledge on the problem the first phase of the inquiry ended with the researcher providing recommendations based on his own perspective.

The first phase of the inquiry is associated with the Lewinian Philosophy by Kurt Lewin the father of action research and social action. His Unfreeze first stage is associated with this phase one in which the researcher came up with this information on the problem as a requirement based on the lived experiences of the participants.

The recommendations were to be used as action agenda for change questions at the commencement of the second phase of the inquiry as shown hereunder:

\subsection{How can Prevention Counselling Strategies for Gender Based Violence be Developed Using the Participatory Approach?}

\subsubsection{Innovation Creation Using Victims Through Social Action}

Having provided the recommendation in form of a question (How can we develop a curriculum on gender to be learnt by soldiers in order to come up with prevention counselling strategies gender based violence).

This was used as an action agenda for change question at the commencement of the second phase as per requirement in order to come up with prevention counselling strategies from a selected group of selected victims. This was The special gendered focus group gave divergent views to the researcher.

After reading through the findings, it was expected that the researcher gives meaning and interpretation to the findings. While the researcher bracketed his pre-conceived ideas throughout the special gendered focus group discussion, this time around was at liberty to give meaning to the findings. This dual action fits into the interpretive phenomenology, which is also called the Haiddegerian Phenomenology. Its major proponent was Martin Heidegger (Egaden, 2012). This strategy emphasizes subjective interpretation of meanings of texts and is commonly used in legal studies were legal researchers tend to interpret texts in various legal documents especially statutes and case reports. In doing so, they read and scrutinize legal texts in order to give meanings contained therein with the purpose of facilitating the application of laws in a justifiable manner.

Furthermore, Theologians use the same strategy to explain and give meaning to biblical text in light of the present happenings. Similarly, Feminist Researchers who try to bring social change by transforming gender power relations such as coming up with prevention counselling models for gender based violence using the participatory approach through social action research process give meaning to findings of the participants (Egaden, 2012). It is against this background that the researcher used the same strategy, which is also known as Hermeneutic Emancipation to come up with a "Quadruple Participatory Prevention Counselling Model for Gender Based Violence among soldier's families in Zambia." This came after he had given meaning to the findings which was later adopted by the group after consensus building by the researched and the researcher had been reached.

What is noted is that soon after this adoption the approach is collapsed and replaced with the term model. This in line with the social action requirement because it becomes a localized model based on the contributions of the victims and the researcher as shown hereunder: 
Developing a Gendered Participatory Prevention Counselling Approach for Gender Based Violence among Soldiers Families in Eastern, Zambia.

\subsection{The Quadruple Participatory Prevention Counselling Model for Gender Based Violence} among Soldiers Families.

\section{INDUCTION OF MILITARY GENDERED COUNSELLING - STAGE 1}

Developing a Gender Counselling Curriculum from relevant organization such as University of Zambia, Ministry of Gender by Gender Desk at Army

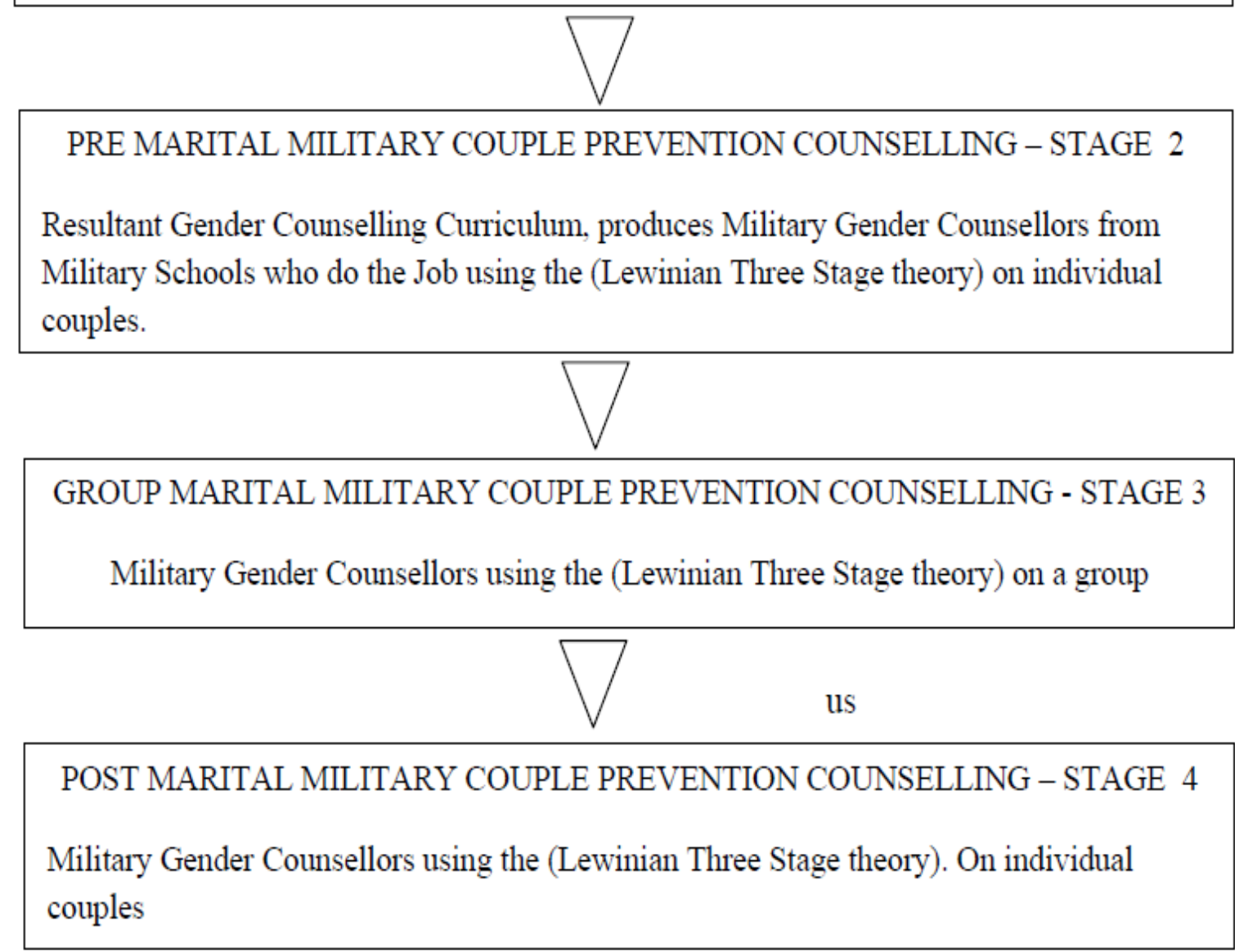

Source: Field Data: 2007

\subsection{Explanatory Meaning of Quadruple Participatory Prevention Counselling Model for Gender Based Violence among Soldiers Families in Zambia.}

\subsubsection{Induction of Military Gendered Counselling-Stage One.}

This is where the gender desk at Army headquarters is tasked to develop a gender curriculum related to the military which should a component of counselling on gender based violence. The material is to be sourced from organizations such as the United Nations Gender Desk, University of Zambia, Gender Department, Ministry of Gender and the Zambia National Lobby for Women. In this way the gender desk will bring an inclusive military gender curriculum.

Upon getting the relevant material it is subjected to scrutiny by the training branch at the military headquarters. The resultant curriculum is piloted for the first class at the military establishment of Zambia by University of Zambia graduates in the related fields such as curriculum and gender.

It is done in corroboration with the university of Zambia in terms of accreditation at the onset.

The graduates are called Gender military focal point counsellors who will be posted to all areas of command which is decentralizing.

The start point is to work with command in that those applying for marriage have to undergo gender counselling before marriage. 


\subsubsection{Pre Marital Military Couple Prevention Counselling - Stage 2}

This stage has produced Gender military focal point counsellors at all categories of command up to the lowest level. This important office is furnished with information on military couples that intend to get married.

The type of counselling will be focused gender based violence oriented but with some general information that may lead to the vice.

In order for this to take place in the most effective manner it should take into consideration the principles of counselling shown hereunder;

- Availability of two parties; meaning that there shall always be two parties the helping party who is a gender military focal point counsellor and the party that is being helped who are the military couple living within the barracks who need help.

- Mutual agreed relationship; The two parties must agree where the other says they are willing to assist while the other agree to be assisted.

- Helping relationship to clarify their ideas; The helper who is the counsellor must begin by listening to their client and get the ideas that will lead to behavioral modification or change after the consumption of ideas from the helper.

- Process not a one-off activity; The helper and the one being helped should agree on other future meetings in order to completely prevent gender based violence through change of behavior using the modified counselling process. Ndhlovu (2015).

Three stage prevention counselling process;

Unfreezing Counselling Stage: At this stage a convenient meeting place for both parties. This is followed by a greeting and purpose of the meeting.

This stage involves the release of information that can cause the problem both at individual and couple levels.

Change Behavioral Counselling Stage: This stage involves the counsellor provision of the strategies for behavioral change both at individual and couple level.

Refreeze Counselling Stage: This is an agreed period of reviewing of the progress on the change behavior in terms of understanding.

\subsubsection{Group Marital Military Couple Prevention Counselling - Stage 3}

Three stage prevention counselling process;

Unfreezing Counselling Stage: At this stage a convenient meeting place for both parties. This is followed by a greeting and purpose of the meeting.

This stage involves the release of information that can cause the problem both at group couple levels.

Change Behavioral Counselling Stage: This stage involves the counsellor provision of the strategies for behavioral change both at group couple level.

Refreeze Counselling Stage: This is an agreed period of reviewing of the progress on the change behavior in terms of understanding.

\subsubsection{Post Marital Military Couple Prevention Counselling - Stage 4}

Three stage prevention counselling process;

Unfreezing Counselling Stage: At this stage a convenient meeting place for both parties. This is followed by a greeting and purpose of the meeting.

This stage involves the release of information that can cause the problem both at group couple levels.

Change Behavioral Counselling Stage: This stage involves the counsellor provision of the strategies for behavioral change both at group couple level.

Refreeze Counselling Stage: This is an agreed period of reviewing of the progress on the change behavior in terms of understanding. 
Developing a Gendered Participatory Prevention Counselling Approach for Gender Based Violence among Soldiers Families in Eastern, Zambia.

3.6.5. Conceptual Framework Contexualisation With Study Findings

CONCEPTUAL FRAMEWORK: On development of a prevention participatory prevention counselling approach based on victim ideas.

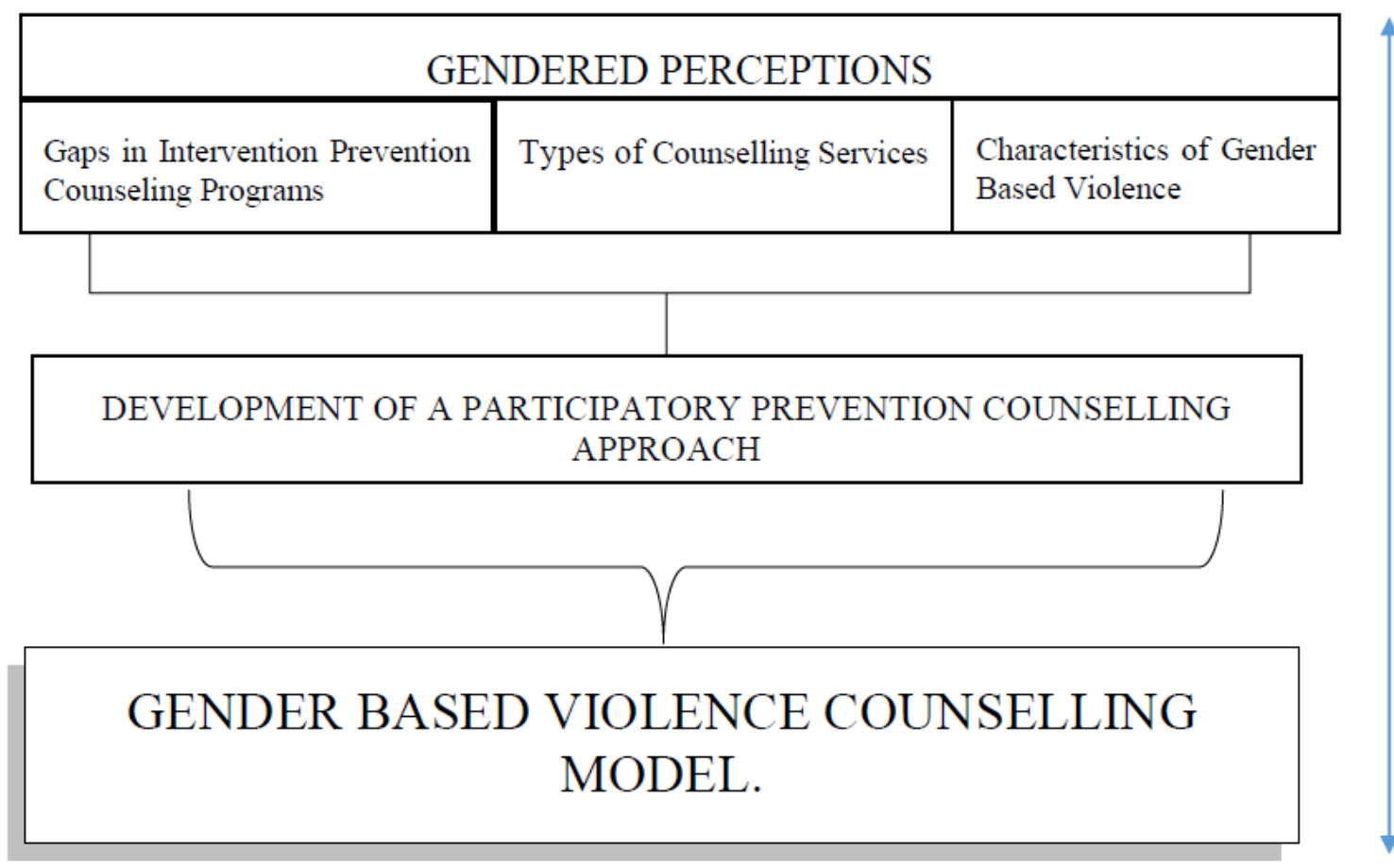

(GRAPHICAL FORM) FIGURE

Conceptual Framework Analysis: Conceptualization of concepts show how Gendered perceptions on the prerequisite standardized questions or constructs on the existing gaps in intervention prevention counselling programs, types of prevention counselling programs and characteristics of gender based violence lead to the development of a participatory prevention counselling approach through the participatory approach using the social action principles resulting into a localized model as the research output once given meaning and adopted by the victims and the researcher.

Having come up with the new innovation it shows that the conceptual framework has fitted into this study.

\subsubsection{Summary of the Second Phase of the Inquiry as Per Requirement of the Research Principles and Approach.}

The aim of the second phase of the inquiry was to come up with a localized model through the use of the pre-determined question called the action agenda for change question. This is used with a selected group of participants under the guidance of the researcher who exercises phenomenological reduction or epoche or Bracketing of preconceived ideas in order to have a full description of the views through the participatory approach Egaden (2012).

The researcher proceeds to give meaning to the ideas leading to the dropping of the approach into a model because it is a localized in house inquiry.

The Second phase of the inquiry is associated with the Lewinian Philosophy by Kurt Lewin the father of action research and social action. His Change stage is associated with this phase twoin which the researcher and the researched adopt a model.

The Localized Model as per requirement stimulates further research involving the third stage although for the purpose of this inquiry it ends here.

\section{CONCLUSiON}

The conclusion of the whole matter has shown how pre requisite standardized knowledge on the problem of the development of prevention counselling strategies on Gender Based Violence at 
individual and group level led the researcher into providing of recommendations as per requirement in the first phase of the inquiry.

The knowledge of the problem as per requirement was on the assessment of the existing gaps in the intervention prevention counselling programs. This marks the start point for all prevention studies that use social action and it was found that no formal programs existed. The other knowledge was on the types of counselling services in which the findings established non formal types of counselling from some stakeholders hence omission of some important counselling principles. The last type of this knowledge was on the characteristics of gender based violence in which Physical and Emotional violence were established as per requirement in the first phase of the inquiry leading to the provision of the recommendations for use in the second phase of the inquiry.

The recommendation was used as an action agenda for change predetermined question by the researcher in order to come up with prevention counselling strategies from a selected gendered group using the participatory approach completing the social action process. Once the researcher gave meaning and it was adopted by the group a model was the resultant research output.

\section{FUtURE Proposed RECOMMENDATIONS FOR FURTHER STUdies.}

This localized innovation model for this study is supposed to undergo a further scientific inquiry. This will be after it has been utilized for period of five years. Then the third phase of the inquiry can be undertaken which is the evaluation. This will be dual in nature in that it will combine the monitoring and evaluation with the scientific inquiry part. It should do this in the light of the prescribed tenets of evaluation which are efficiency, effectiveness, impact, sustainability and the relevance of the localized model from how it is developing in terms of usage. The tenets are fitted into the specific objectives with a view of modifying the model. This phase three is semi-independent due to the period taken before the refreeze stage of Kurt lewin.

It is also recommended that another independent study be conducted using the principles of social action but regarding the civilian population that have different characteristics from those of the military in the same area. This because the military are a fraction of the civilian population in general.

\section{REFERENCES}

[1] Central Statistical Office (2007) Zambia Demographic Health Survey, Central Statistical Office, Lusaka.

[2] Creswell, J. W. (2007). Qualitative Inquiry and Research Designs: Choosing Among Five Approaches, $2^{\text {nd }}$ ed. Sage Publishers, London.

[3] Egaden, C.L. (2012). Participatory Action/Toolkit Procedure using Future Search Research: A Modern Thought for Doctoral and Post-Doctoral Students, Sage Publications, London.

[4] Guba and Lincoln, J. (1994). Qualitative Research, Sage Publications, London.

[5] GRZ, (2011). Anti-Gender Based Violence Act Number one of 2011

[6] Holahan, C and Moors R (1997) Personal and contextual determinants of coping strategies on gender based violence. Journal on personal and social psychology 62, p 846 to 867.

[7] Malekinejad, M.; Johnston, L.G.; Kendall C; Kerr, L.R.; Rifkin, M.R., and Rutherford, G.W., (2008) Using Respondent-Driven Sampling Methodology for HIV Biological and Behavioral Surveillance in International Settings: A Systematic Review. AIDS and Behavior, 12, S105-S130.

[8] Merriam, C. (2015) Developing a female preventive participatory approach to prevent sexual harassment on female officer cadets, Journal of issues, 2015. 62 (2) 212-235

[9] Mohammed, G. (2014). Atlas T17 Qualitative Data Analysis Software: Principles and Practice, Penguin Publishers, New York.

[10] Mutakwa, E. (2016). Trends and Patterns of Gender based Violence and Help seeking behavior in Zambia: A case of old Market compound of lukulu. Unza press, Dissertation. Lusaka.

[11] Musune. J. (2015). Domestic Violence against men, Unza Dissertation, lusaka.

[12] Msabila, T. and Nalaila, G. (2013). Research Proposal and Dissertation Writing: Principles and Practice, Nyambari Publishers, Dar es Salaam.

[13] Ndhlovu, D. (2015). Theory and Practice of Guidance and Counselling, University of Zambia press, lusaka.

[14] Swart.E. (2011). Strategies for coping with Gender Based Violence: A study of young women in kiberia, Kenya University of Central Florida. 
Developing a Gendered Participatory Prevention Counselling Approach for Gender Based Violence among Soldiers Families in Eastern, Zambia.

[15] World Health Organization. (2008). Challenges faced in curbing Gender Based Violence in Sub-Saharan Countries. United Nation Publications. New York.

[16] World Vision (2015). An Assessment of Established One Stop Counselling Centers for Gender Based Violence. United Nations Publishers New York.

\section{AUTHOR'S BIOGRAPHY}

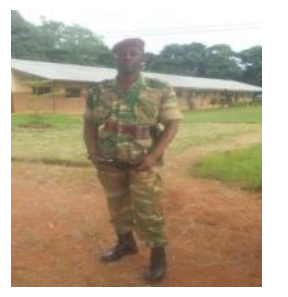

John Mwitumwa Matakala is a Doctor of Philosophy Research Fellow in Gender Studies. At the University Of Zambia. He is a main Researcher in this inquiry. He is also Special Force Soldier in the Commando Unit.

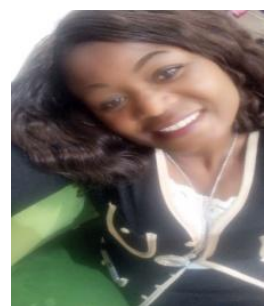

Margaret Milochi Nzima is a Doctor of Philosophy Research Fellow in Guidance and Counselling Studies at the University of Zambia. She is a Researcher in this Inquiry. She is a Part Time Lecturer at the University of Zambia and University of Africa.

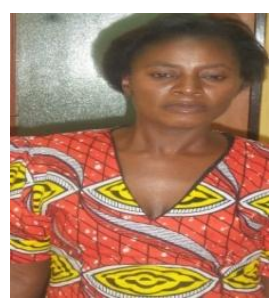

Ivy Nawa Akabondo is a Master of Art in Gender Studies? At the University of Zambia. She Is the Main Researcher in this Inquiry. She has a Bachelor of Arts Degree in History and Religious Studies from the University of Zambia.

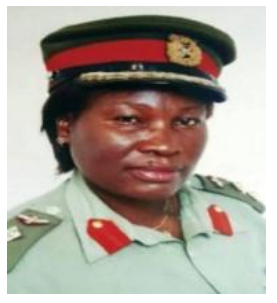

Dr. Annie Namakando -Phiri (Col) The Doctor of Public Healthy /Epidemiology/ Gender. She Is Also A Senior Retired Army Officer. Was a Head of Department - 2013 To 2016. At The University Of Zambia. She is a the Main Supervisor in This Research Inquiry and Phenomenological Advisor in This Inquiry Senior Lecturer/Researcher - Department Of Gender Studies

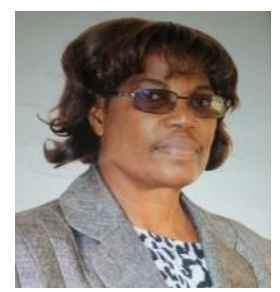

Prof. Mubiana Macwan'gi, the Professor of Public Health The Principal Supervisor of the Study. Was the Institute of Economic and Social Research Director - 2010 to 2016 at the University of Zambia. She is a Research and Innovation Advisor in this Inquiry. Senior Lecturer/Researcher - Department of Gender Studies

Citation: John Mwitumwa Matakala, et.al. "Developing a Gendered Participatory Prevention Counselling Approach for Gender Based Violence among Soldiers Families in Eastern, Zambia." International Journal of Humanities Social Sciences and Education (IJHSSE), vol 5, no. 9, 2018, pp. 68-84. doi: http://dx.doi.org/10.20431/2349-0381.0509011.

Copyright: (0) 2018 Authors. This is an open-access article distributed under the terms of the Creative Commons Attribution License, which permits unrestricted use, distribution, and reproduction in any medium, provided the original author and source are credited. 